\title{
Regulation of the Amorphous Supermolecular Structure of High-Speed-Spun Poly(ethylene terephthalate) Fibers by High Temperature Short Period Heat-Treatment
}

\author{
Kenji Kamide, Tomio KuRIKI, and Sei-ichi MANABE \\ Fundamental Research Laboratory of Fiber and Fiber-Forming Polymers, \\ Asahi Chemical Industry Co., Ltd., 11-7 Hacchonawate, \\ Takatsuki, Osaka 569, Japan \\ (Received July 5, 1985)
}

KEY WORDS Amorphous Region / Supermolecular Structure / Poly-
(ethylene terephthalate) / Heat-Treatment / Dynamic Loss Tangent /

We found in a recent study ${ }^{1}$ of the dynamic loss tangent, $\tan \delta$, of as-spun poly(ethylene terephthalate) (PET) fibers that the distribution of molecular packing density in the amorphous region became broader with increasing spinning velocity $V_{\mathrm{s}}$ when $V_{\mathrm{s}}$ was higher than $6 \mathrm{~km} \mathrm{~min}^{-1}$. In other words, the part with lower packing density was enhanced with increasing $V_{\mathrm{s}}$. Here, $V_{\mathrm{s}}$ was measured as the surface velocity of a take-up winding roller. These experimental results are contrary to an intuitive prediction derived from the experiment at low $V_{\mathrm{s}}\left(<4-5 \mathrm{~km} \mathrm{~min}^{-1}\right)$. As this indicates, the supermolecular structure of as-spun PET fibers varies obviously, depending on $V_{\mathrm{s}}$ and there is a large possibility of controlling the supermolecular structure by the selection of adequate spinning and heat-treatment conditions. Note that the fibers for textile use are usually very fine (i.e., less than $20 \mu \mathrm{m}$ in diameter) and attain the desired temperature within a relatively short period by conventional heat-treatment.

In this note, we demonstrate that the amorphous supermolecular structure of as-highspeed spun PET fibers can be controlled by treating the fibers for a short period at high temperature.

\section{EXPERIMENTAL}

As-spun PET fibers are the same as those employed before. ${ }^{1}$

The heat-treatment apparatus shown in Figure 1 was constructed at our laboratory. PET fibers were heat-treated by running them through a tube heater, which was maintained at a constant temperature $T_{\mathrm{a}}$. The heating period $t_{\mathrm{a}}$ was adjusted by choosing a surface velocity of the delivery roller (6) in Figure 1).

The conditions of heat-treatment utilized here are summarized in Table I. Here, the feed ratio $F_{\mathrm{r}}$ is defined as follow:

$$
\begin{aligned}
& F_{\mathrm{r}}(\%) \\
& =\left(1-\frac{\text { surface velocity of delivery roller }}{\text { surface velocity of feed roller }}\right) \times 100
\end{aligned}
$$

\section{RESULTS AND DISCUSSION}

Figure 2 shows the effects of the heattreatment temperature $T_{\mathrm{a}}$ on the $\tan \delta$ peak value $(\tan \delta)_{\max }$ and its temperature $T_{\max }$, observed in the $\tan \delta$-temperature curve in the range of $50-200^{\circ} \mathrm{C}$. In the figure, $t_{\mathrm{a}}$ was taken 


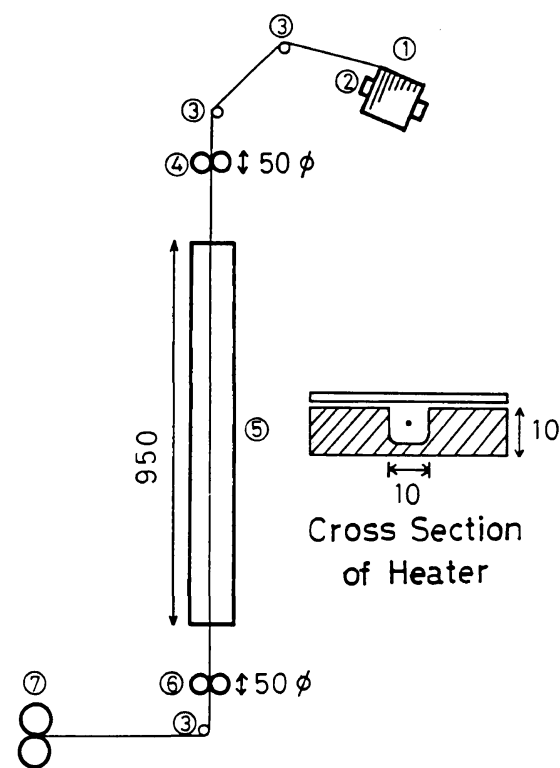

Figure 1. Apparatus for heat-treatment of as-spun PET fibers: (1), supplying fibers; (2), paper bobbin; (3), deflecting pin; (4), feed roller; (5), tublar hear-treatment zone; (6), delivery roller; (7), winding roller.

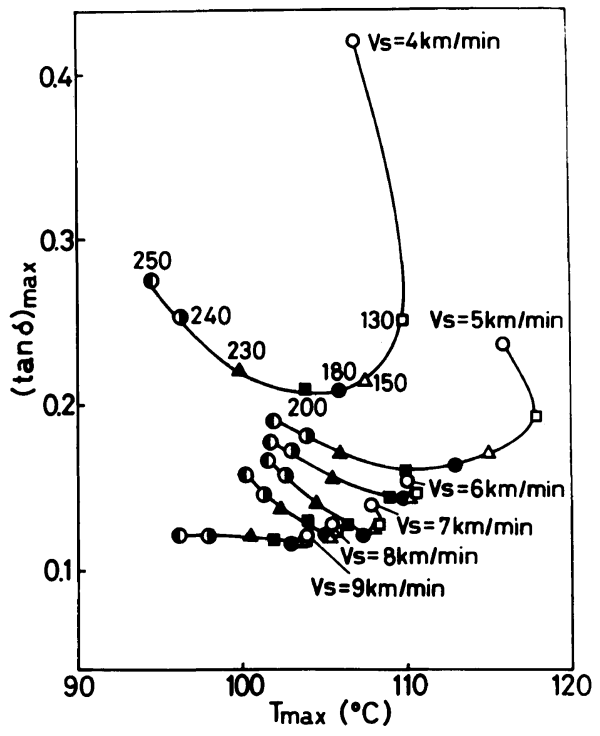

Figure 2. Effects of heat-treatment temperature $T_{\mathrm{a}}$ on the relations between $(\tan \delta)_{\max }$ and $T_{\max }$ of as-spun PET fibers. Number on curve is $T_{\mathrm{a}}\left(t_{\mathrm{a}}=1 \mathrm{~s}, F_{\mathrm{r}}=0 \%\right)$.

as $1 \mathrm{~s}$. The unfilled circles in the figure correspond to original as-spun PET fibers. In the range of $V_{\mathrm{s}}=4-7 \mathrm{~km} \mathrm{~min}^{-1},(\tan \delta)_{\max }$ ini-
Table I. Heat-treatment conditions

\begin{tabular}{ccccc}
\hline $\begin{array}{c}\text { Sample } \\
\text { series }\end{array}$ & $V_{\mathrm{s}} / \mathrm{km} \mathrm{min}^{-1}$ & $T_{\mathrm{a}} /{ }^{\circ} \mathrm{C}$ & $t_{\mathrm{a}} / \mathrm{s}$ & $F_{\mathrm{r}} / \%$ \\
\hline I & $2-9$ & $130-250$ & $0.2-1.0$ & 0 \\
II & 5.5 and 8.0 & $190-250$ & $0.5-2.0$ & 0
\end{tabular}

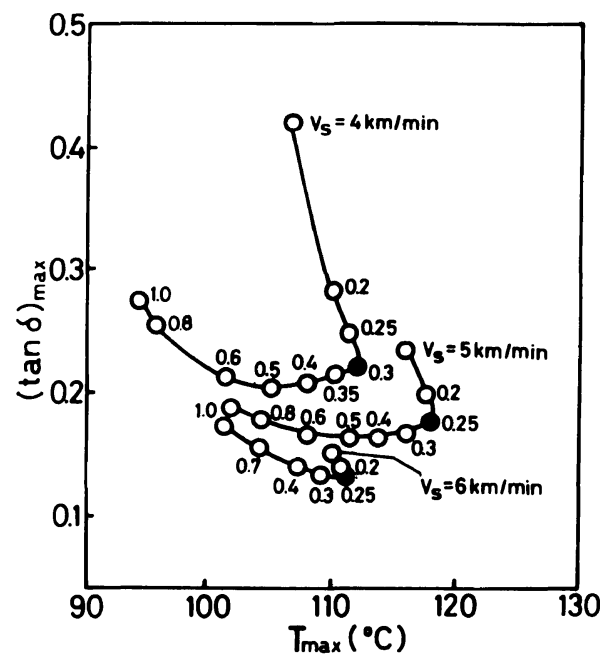

Figure 3. Effects of heat-treatment period $t_{\mathrm{a}}$ on the relations between $(\tan \delta)_{\max }$ and $T_{\max }$ of as-spun PET fibers, Number on curve is $t_{\mathrm{a}}\left(T_{\mathrm{a}}=250^{\circ} \mathrm{C}, F_{\mathrm{r}}=0 \%\right)$.

tially decreases with increasing $T_{\mathrm{a}}$, and then increases after passing a minimum. For example, $T_{\mathrm{a}}$ giving the minimum $(\tan \delta)_{\max }$ are $180^{\circ} \mathrm{C}$ at $V_{\mathrm{s}}=4,6$ and $9 \mathrm{~km} \mathrm{~min}^{-1}$, and $200^{\circ} \mathrm{C}$ at $V_{\mathrm{s}}=5 \mathrm{~km} \mathrm{~min}^{-1}$. Here, with an increase in $T_{\mathrm{a}}, T_{\max }$ of the heat-treated PET fiber spun at $V_{\mathrm{s}}=4-5 \mathrm{~km} \mathrm{~min}^{-1}$ increases if $T_{\mathrm{a}}$ is lower than a specific temperature and decrease if $T_{\mathrm{a}}$ is above the temperature. The $(\tan \delta)_{\max }$ of the heat-treated fiber spun at $V_{\mathrm{s}}=9 \mathrm{~km} \mathrm{~min}^{-1}$ remains almost constant, irrespective of $T_{\mathrm{a}}$, but $T_{\max }$ decreases with an increase in $T_{\mathrm{a}}$.

Figure 3 shows the effects of the period of heat-treatment $t_{\mathrm{a}}$ at $T_{\mathrm{a}}=250^{\circ} \mathrm{C}$ on $(\tan \delta)_{\max }$ and $T_{\max }$ of the heat-treated PET fibers spun at $V_{\mathrm{s}}=4,5$ and $6 \mathrm{~km} \mathrm{~min}^{-1}$ and heat-treated at a constant $F_{\mathrm{r}}(0 \%)$. The number in the figure is $t_{\mathrm{a}}$ in $\mathrm{s}$. In a small $t_{\mathrm{a}}$ region, $(\tan \delta)_{\max }$ decreases with shifting $T_{\max }$ to a higher temperature. If 


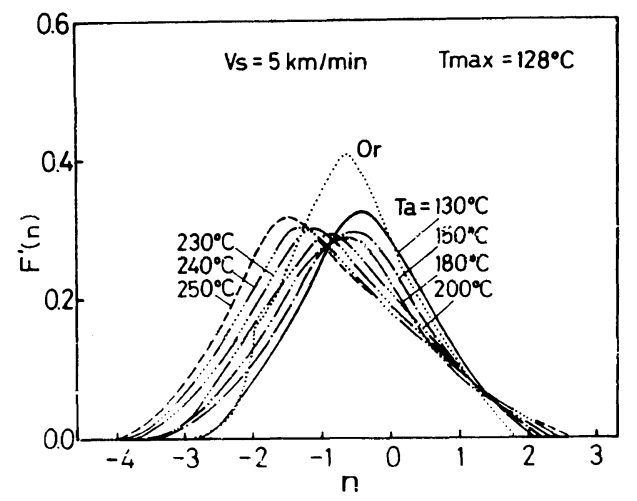

Figure 4. Effects of heat-treatment temperature $T_{\mathrm{a}}$ on the amorphous molecular packing density distribution $F^{\prime}(n)$ of annealed as-spum PET fibers with $V_{\mathrm{s}}=5.5 \mathrm{~km} \mathrm{~min}^{-1}$ for $1 \mathrm{~s}$ at $F_{\mathrm{r}}=0 \%$ : Or. means original fiber.

$t_{\mathrm{a}}$ is longer than a specific value $t_{\mathrm{a}, \mathrm{t}}$ (for example, $t_{\mathrm{a}, \mathrm{t}}$ were $0.3 \mathrm{~s}$ at $V_{\mathrm{s}}=4 \mathrm{~km} \mathrm{~min}^{-1}$ and $0.25 \mathrm{~s}$ at $V_{\mathrm{s}}=5$ and $6 \mathrm{~km} \mathrm{~min}^{-1}$ ), the $(\tan \delta)_{\max }$ has a tendency to increase with $t_{\mathrm{a}}$, but $T_{\max }$ shifts greatly to a lower temperature. The specific time $t_{\mathrm{a}, \mathrm{t}}$ shown by the filled mark in the figure is a kind of turning point. In $t_{\mathrm{a}}<t_{\mathrm{a}, \mathrm{t}}$ region, a significant increase in the crystallinity during the heat-treatment was observed by X-ray diffraction experiments. In $t_{\mathrm{a}}>t_{\mathrm{a}, \mathrm{t}}$, the recrystallization was negligible and loosening in the amorphous region occurred.

Figure 4 shows the effects of the temperature $T_{\mathrm{a}}$ on the molecular packing density distribution $F^{\prime}(n)$ of the heat-treated PET fibers spun at $V_{\mathrm{s}}=5 \mathrm{~km} \mathrm{~min}^{-1}$ and annealed for $t_{\mathrm{a}}=1 \mathrm{~s}$, where $n$ is the molecular packing density in the amorphous region. The evaluation of $n$ is made by the Manabe-Kamide (MK) theory ${ }^{2-6}$ of the $\tan \delta$-temperature curve. In the figure, $T_{\max }=128^{\circ} \mathrm{C}$ means the peak temperature of $\tan \delta$ of a standard sample where $n$ is zero, and this value of $T_{\max }$ corresponds to that of the conventional drawn fiber. If asspun fibers are heat-treated at $T_{\mathrm{a}}<130^{\circ} \mathrm{C}$, the amorphous portion, especially the portion of the amorphous region having lower packing density becomes remarkably smaller with keeping the high $n$ portion unchanged. As $T_{\mathrm{a}}$ increases further, a large amount of amorphous portion with $n$ lower than the lower limit of untreated fibers brings about a significant increase and concurrently a small amount of $n>2$ region increases slightly. This means that the heterogeneity of the amorphous region increases at higher $T_{\mathrm{a}}$. The elastic modulus fraction $f_{\mathrm{e}}$ contributing to $\alpha_{\mathrm{a}}$ dispersion ${ }^{7}$ decreases first and then very slightly increases with $T_{\mathrm{a}}$.

Figure 5 shows the effects of $t_{\mathrm{a}}$ on $F^{\prime}(n)$ of heat-treated PET fibers spun at $V_{\mathrm{s}}=$ $8 \mathrm{~km} \mathrm{~min}^{-1}$ and annealed at $T_{\mathrm{a}}=250^{\circ} \mathrm{C}$. The amorphous region with low packing density of heat-treated fibers increases with $t_{\mathrm{a}}$ for $t_{\mathrm{a}}>0.5 \mathrm{~s}$.

As illustrated in Figures 4 and 5, we can prepare PET fibers with an amorphous region having lower packing density as compared with the original as-spun PET fiber, if proper heat-treatment conditions $\left(V_{\mathrm{s}}, T_{\mathrm{a}}, t_{\mathrm{a}}\right)$ are selected for each given as-high-speed-spun PET fiber. As-spun fibers spun at $V_{\mathrm{s}}=4$ $5 \mathrm{~km} \mathrm{~min}^{-1}$ and probably $5-6 \mathrm{~km} \mathrm{~min}^{-1}$ contain two different amorphous regions: a predominantly large portion of region 1 and a small portion of region 2. By annealing these fibers at a temperature just below their melting points, the greater part of amorphous region 1 is transformed into region 2. For example, we obtained an apparent activation energy ${ }^{5}$ $\Delta H_{\mathrm{a}}=78.2 \mathrm{kcal} \mathrm{mol}^{-1}$ for heat-treated $\left(T_{\mathrm{a}}=\right.$ $249^{\circ} \mathrm{C}, t_{\mathrm{a}}=0.84 \mathrm{~s}, F_{\mathrm{r}}=0 \%$ ) as-spun PET fibers spun at $V_{\mathrm{s}}=4.5 \mathrm{~km} \mathrm{~min}^{-1}$, and $\Delta H_{\mathrm{a}}=54.8$ $\mathrm{kcal} \mathrm{mol}^{-1}$ for region 1 of the untreated fibers spun at $V_{\mathrm{s}} \geqq 4 \mathrm{~km} \mathrm{~min}^{-1}$. The amorphous region of as-spun fibers spun at $V_{\mathrm{s}} \geqq$ $7 \mathrm{kmmin}^{-1}$ is almost region 2, whose average packing density becomes lower by similar annealing, and the ethyleneglycol units in PET chains were confirmed by an infra-red spectroscopic study to have a large tendency of trans configuration.

The $\Delta H_{\mathrm{a}}$ is governed by the segment size of 


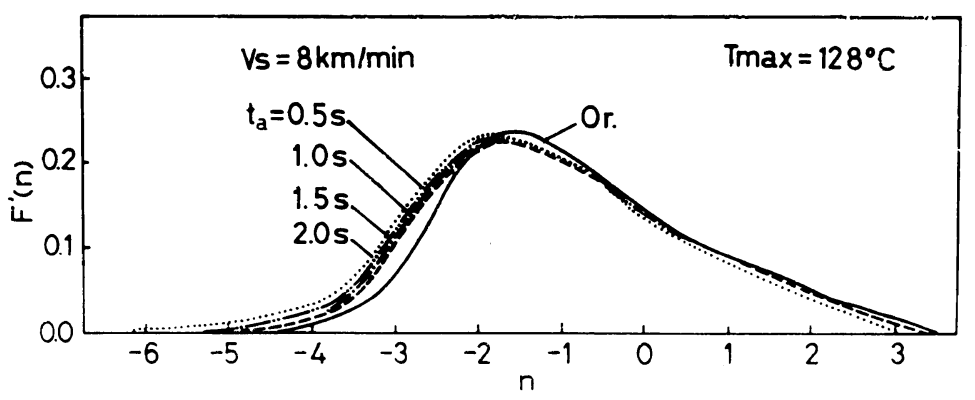

Figure 5. Effects of heat-treatment period $t_{\mathrm{a}}$ on the amorphous molecular packing density distribution $F^{\prime}(n)$ of annealed as-spun PET fibers with $V_{\mathrm{s}}=8 \mathrm{~km} \mathrm{~min}^{-1}$ at $T_{\mathrm{a}}=250^{\circ} \mathrm{C}$ and $F_{\mathrm{r}}=0 \%$ : Or. means original fiber.

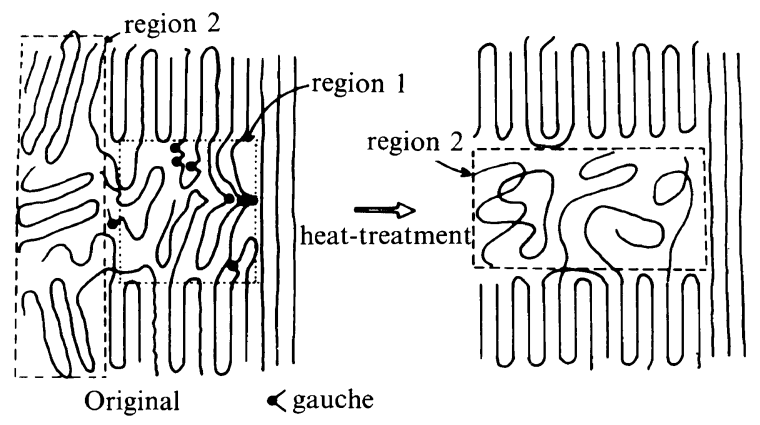

Figure 6. Schematic representation of supermolecular structure of PET fibers: (a), as-spun fiber; (b), annealed as-spun fiber.

molecular movement and the intermolecular interaction. The value of $T_{\max }$ for the heattreated fiber is lower than that of the sample before heat-treatment, indicating that the intermolecular interaction and the packing density decrease with the heat-treatment. Therefore, the segment size of molecular movement in the region 2 is larger than that in the region 1 . In addition to this, the gauche configuration of ethyleneglycol unit decreases with the heat-treatment. The change in supermolecular structure of as-spun PET fibers during the above heat-treatment is schematically demonstrated in Figure 6. In the figure, the filled circle indicates PET chains with the gauche configuration of the ethyleneglycol unit.

\section{REFERENCES}

1. K. Kamide, S. Manabe, and T. Kuriki, Polym. J., 18, 173 (1986).

2. S. Manabe, K. Kamide and C. Nakayama, J. Text. Mach. Soc. Jpn., 30, T45 (1977); and also J. Text. Mach. Soc. Jpn., English Edition, 26, 1 (1980).

3. S. Manabe, K. Kamide and C. Nakayama, J. Text. Mach. Soc. Jpn., 30, T55 (1977); and also J. Text. Mach. Soc. Jpn., English Edition, 26, 42 (1980).

4. S. Manabe, K. Kamide, and C. Nakayama, J. Text. Mach. Soc. Jpn., 30, T66 (1977); and also J. Text. Mach. Soc. Jpn., English Edition, 26, 65 (1980).

5. S. Manabe, K. Kamide, C. Nakayama, and S. Kobayashi, J. Text. Mach. Soc. Jpn., 30, T85 (1977); and also J. Text. Mach. Soc. Jpn., English Edition, 27, 10 (1980).

6. S. Manabe and K. Kamide, Polym. J., 16, 375 (1984).

7. K. Kamide, S. Manabe, M. Hara, and C. Nakayama, J. Text. Mach. Soc. Jpn., 31, T1 (1978). 